\title{
Hunter Syndrome (Mucopolysaccharidosis II) - The Signs and Symptoms a Neurologist Needs to Know
}

\author{
Hernan Amartino \\ Head of Child Neurology Department, Hospital Universitario Austral, Buenos Aires, Argentina
}

\begin{abstract}
Hunter syndrome (mucopolysaccharidosis II) is a rare X-linked lysosomal storage disease caused by deficiency of the enzyme iduronate-2sulfatase. The condition is one of a group of disorders, the mucopolysaccharidoses, which all result in accumulation of glycosaminoglycans. Hunter syndrome is a chronic progressive disorder whose clinical manifestations vary widely in severity and involve multiple organs and tissues. In addition to developing somatic symptoms, patients having the neuronopathic form of the disease also display developmental delay and cognitive impairment in early childhood that progressively worsens and that is severely life-limiting. Patients are at risk of developing secondary neurological manifestations, including hydrocephalus, vision and hearing loss, carpal tunnel syndrome and spinal cord compression. Common findings from brain magnetic resonance imaging (MRI) scans and at autopsy include neurodegenerative changes in white matter, the corpus callosum and basal ganglia; enlargement of periventricular spaces; ventriculomegaly; closed cephaloceles; and tissue atrophy. Though at present there is no specific treatment for the neurodegenerative aspects of the disease, hydrocephalus, carpal tunnel syndrome and spinal cord compression can be managed surgically. Patients who have Hunter syndrome should receive coordinated care from a multidisciplinary team: in light of the extensive neurological symptoms of the disease, neurologists play an important role in the diagnosis and management of this condition.
\end{abstract}

\section{Keywords}

Hunter syndrome, mucopolysaccharidosis II, lysosomal storage disorder, developmental delay, cognitive impairment, neurology, neurological symptoms, seizures, spinal cord compression, neuronopathic

Disclosures: Hernan Amartino is a consultant to Shire and a principal investigator on Shire-sponsored clinical trials.

open Access: This article is published under the Creative Commons Attribution Noncommercial License, which permits any non-commercial use, distribution, adaptation and reproduction provided the original author(s) and source are given appropriate credit.

Acknowledgements: Editorial support was provided by Andy Sheridan from Oxford PharmaGenesis TM and funded by Shire.

Received: 13 March 2015 Accepted: 17 April 2015 Citation: European Neurological Review, 2015;10(1):90-4 DOI: 10.17925/ENR.2015.10.01.90

Correspondence: Hernan Amartino, Jefe del Servicio de Neurología Infantil,Hospital Universitario Austral, Juan Domingo Peron 1500, Pilar (B16641NZ), Buenos Aires, Argentina. E: hernan.amartino@gmail.com

Support: The publication of this article was supported by Shire. The views and opinions expressed are those of the author and do not necessarily reflect those of Shire.

Hunter syndrome (mucopolysaccharidosis II, OMIM 309900), is a rare progressive $\mathrm{X}$-linked lysosomal storage disease caused by deleterious mutations in the iduronate-2-sulfatase (I2S) gene, leading to a deficiency of the enzyme. ${ }^{1,2}$ I2S is required for the catabolism of the glycosaminoglycans (GAGS) dermatan sulphate and heparan sulphate; in the absence of I2S, these GAGs accumulate in tissues and organs. ${ }^{1}$ Hunter syndrome occurs with a reported incidence of 0.3-0.71 per 100,000 live births ${ }^{1,3,4}$ and almost exclusively affects males, though rare cases of females having the disease are known. Patients suspected of having Hunter syndrome are often first screened by assessing urinary GAGS (quantitative and qualitative tests are available). However, a definitive diagnosis requires enzyme assay in leukocytes, fibroblasts, dried blood spots or plasma, using substrates specific for I2S. Molecular testing can confirm the diagnosis and may be used to screen family members when the type of MPS and the family mutation is known. ${ }^{5,6}$

Charles Hunter first described the condition in 1917 in two brothers presenting with developmental delay. ${ }^{7}$ Hunter syndrome is associated with multiple somatic symptoms affecting nearly every organ, including the cardiovascular, respiratory, gastrointestinal and endocrine systems. ${ }^{8}$
Patients also develop characteristic dysmorphic facial features and stunted growth (see Figure 1). ${ }^{8}$

Although the clinical phenotype of Hunter syndrome covers a wide continuous spectrum from mild to severe disease, patients are usually considered to be in one of two groups: those having the severe (neuronopathic) form of the disease and those having the attenuated (non-neuronopathic) form. ${ }^{5,9}$ Approximately two-thirds of patients have neuronopathic Hunter syndrome and develop both the somatic symptoms and cognitive impairment. ${ }^{8}$ This form of the condition is characterised by developmental delay that generally becomes apparent at 2-4 years of age and cognitive decline that occurs from approximately 4 years of age onwards (see Figure 2). ${ }^{8,9}$ Neuronopathic Hunter syndrome is life-limiting, and the natural course of the disorder results in death in the second decade of life..$^{8,10}$ Enzyme replacement therapy (ERT) has been available for almost 10 years in Hunter syndrome and positively affects specific somatic symptoms. ${ }^{11-13}$

Patients having the non-neuronopathic form of Hunter syndrome are more likely to have normal cognitive abilities but may experience some 


\section{Figure 1: Typical Dysmorphic Features in Patients with Hunter Syndrome}

(A)

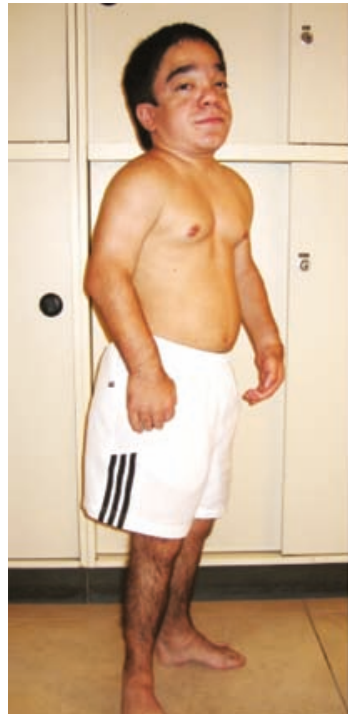

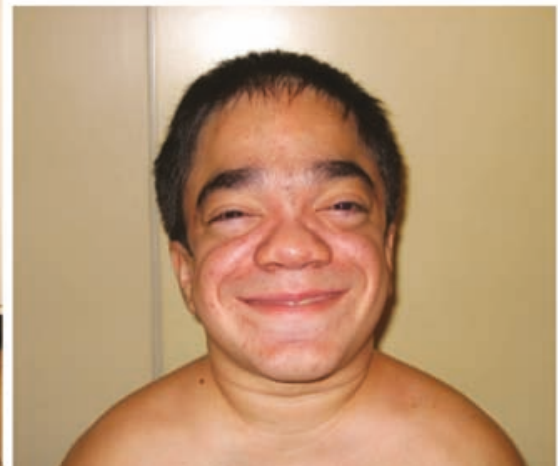

(B)

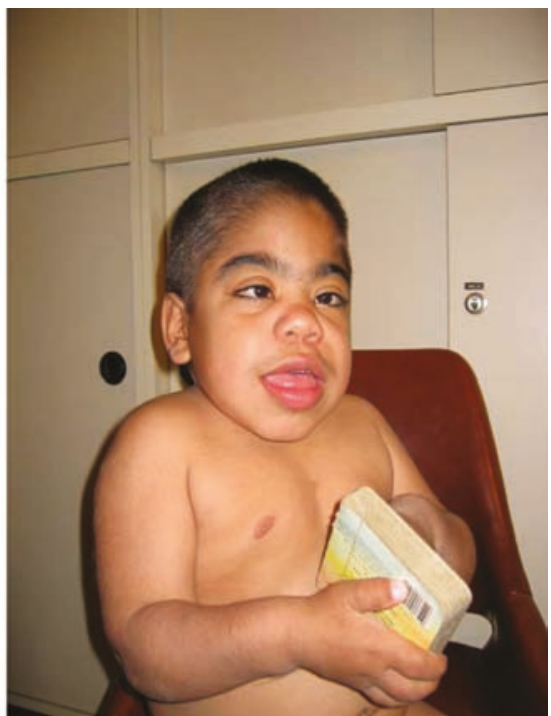

(A) 19-year-old patient with non-neuronopathic Hunter syndrome; (B) 5-year-old patient with neuronopathic Hunter syndrome. Permissions from patients or families were obtained as appropriate.

other neurological disorders related to accumulation of GAGs (e.g., seizures, carpal tunnel syndrome, myelopathy) in addition to somatic symptoms. ${ }^{5,9}$ However, somatic symptoms are themselves life-limiting, and such patients usually die in early adulthood. ${ }^{5,9}$ This article reviews the neurological manifestations of Hunter syndrome and provides information on the diagnosis and management of these manifestations.

\section{Cognitive Decline and Primary Neuronal Parenchymal Involvement}

In the absence of a known family history, general developmental delay is often the neurological presenting symptom that leads to diagnosis of Hunter syndrome. ${ }^{8}$ In neuronopathic Hunter syndrome, children's cognitive, language and motor skills plateau and subsequently decline from the age of 4 years onwards. ${ }^{8,9}$ Behavioural problems often precede cognitive decline and are often the first symptoms parents report. ${ }^{14-16}$ Behavioural problems include tantrums, obstinacy and hyperactivity and can be misdiagnosed as attention deficit hyperactivity disorder or other neurodevelopmental disorders. ${ }^{14-16}$ Children having both forms of Hunter syndrome tend to have hearing loss and limited mobility; this, combined with declining cognitive function in neuronopathic disease, can cause patients to become frustrated and may exacerbate behavioural difficulties. ${ }^{9,15}$ Hyperactivity may appear to lesson with age, but this is usually because patients becoming increasingly physically disabled as the disease progresses. ${ }^{8.9}$ Patients may ultimately enter a vegetative state. ${ }^{89}$ Delays in speech development may occur in conjunction with cognitive decline in severely affected children, and many patients never learn to speak in full sentences. ${ }^{9,14}$ Patients having non-neuronopathic disease may show a delay in acquiring language skills despite normal cognitive development, owing to hearing loss. In some patients, mild residual cognitive disability may occur secondary to early sensorial isolation. ${ }^{9}$ Thus identifying neuronopathic disease can be complicated in some individuals. Sleep disturbances caused by either obstructive apnoea or central apnoea or both are three times more common in patients who have neuronopathic disease than in non-neuronopathic patients, ${ }^{15-17}$ indicating a significant role for neuronal dysfunction. Reported sleep disturbances include difficulty initiating or maintaining sleep, decreased rapid eye movement sleep and sleep onset insomnia. ${ }^{15,17}$ Seizures and seizure-like behaviours also occur early
Figure 2: Cognitive Development in Patients with Neuronopathic (Severe) and Nonneuronopathic (Attenuated) Hunter Syndrome

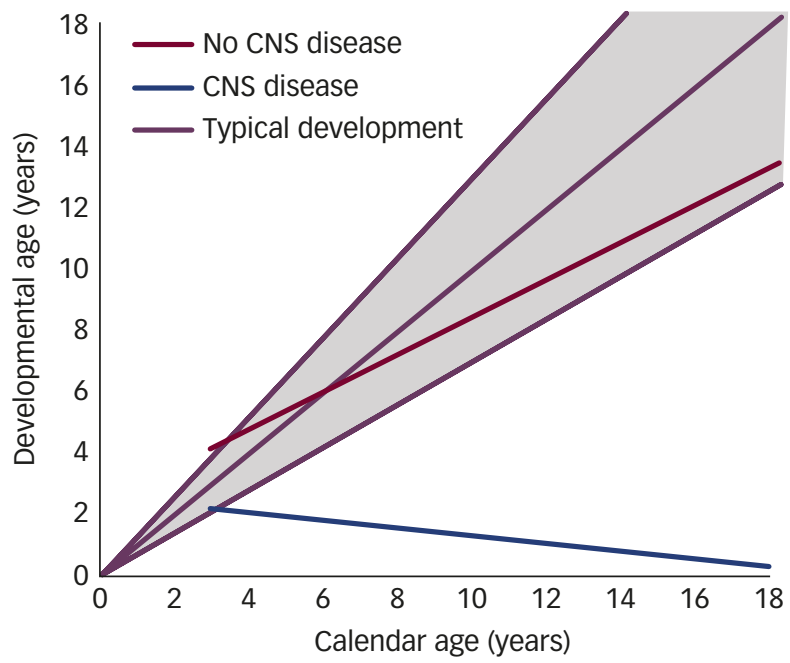

CNS = central nervous system. Reproduced with permission from Holt et al. 2011.15

in the disease. Although more prevalent in those having neuronopathic Hunter syndrome, seizures have been reported in patients having either form of the disease. Tonic-clonic seizures are the most common type of seizure in Hunter syndrome, but absent and myoclonic seizures have also been reported. ${ }^{15}$ It is possible that absence seizures (petit mal) are under-reported; neurologists should be aware of this and seek to determine whether they occur in a patient. Some patients experience more than one type of seizure; if Hunter syndrome has not been suspected, a primary diagnosis of epilepsy may be made. ${ }^{15,18,19}$

\section{Secondary Neurological Disorders}

secondary neurological disorders affecting the central or peripheral nervous systems can be seen in both neuronopathic and nonneuronopathic Hunter syndrome. Some severe problems, such as hydrocephalus, are more common in neuronopathic disease, whereas others disorders (such as carpal tunnel syndrome and spinal cord 


\section{Figure 3: Changes Seen in the Brain in Patients with Hunter Syndrome}

(A)

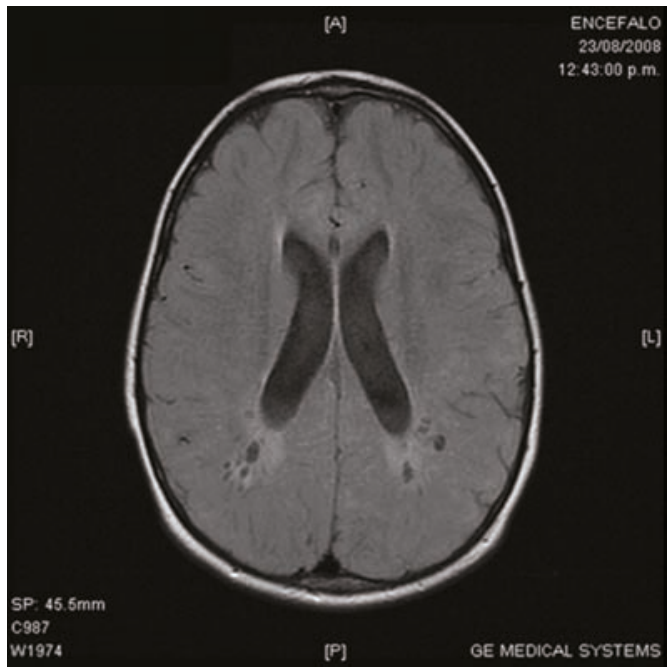

(B)

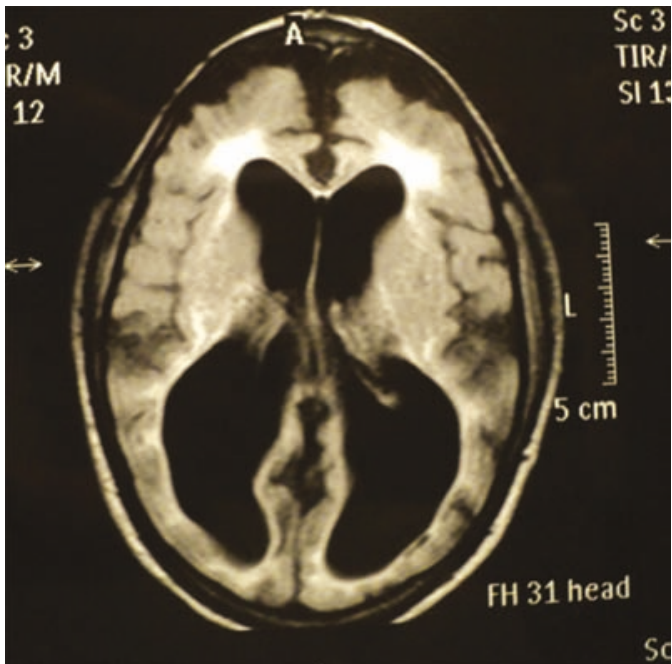

Magnetic resonance imaging (MRI) shows: (A) Honeycomb-like appearance of dilated perivascular spaces in a 3-year-old Hunter syndrome patient; (B) Atrophy, ventriculomegaly and periventricular white matter hyperintense lesions in a 14-year-old Hunter syndrome patient.

\section{Table 1: Suggested Management of the Neurological Symptoms of Hunter Syndrome}

\begin{tabular}{|c|c|c|}
\hline \multicolumn{3}{|c|}{ Management } \\
\hline Neurological Manifestations & Monitoring & Treatment \\
\hline Cognitive impairment & $\begin{array}{l}\text { Neuropsychological testing; hearing } \\
\text { assessment }\end{array}$ & $\begin{array}{l}\text { Stimulating environments; special schooling; } \\
\text { cognitive therapy; speech therapy }\end{array}$ \\
\hline Behavioural problems & Aim to rule out comorbid conditions & $\begin{array}{l}\text { Antipsychotics (typical or atypical); stimulants; mood stabilisers; other } \\
\text { psychiatric agents; behavioural therapy }\end{array}$ \\
\hline Seizures & EEG/polysomnography & Anticonvulsant therapy \\
\hline Sleep disorder & Polysomnography & Melatonin, hypnotics, neuroleptics \\
\hline Hydrocephalus & Brain MRI* & Ventriculoperitoneal shunting \\
\hline Carpal tunnel syndrome & Nerve conduction studies; wrist ultrasound & Decompression surgery \\
\hline Spinal cord compression & Spine MRI; somatosensory evoked potential & Decompression surgery \\
\hline
\end{tabular}

* Lumbar puncture to measure intracranial pressure may be necessary. EEG = electrocardiogram; $M R I=$ magnetic resonance imaging.

compression) are equally likely in both forms of the condition. ${ }^{15}$ Chronic communicating hydrocephalus, which has been hypothesised to be due to impaired resorption of cerebrospinal fluid, occurs in 80-100 \% of patients who have Hunter syndrome. ${ }^{17,20}$ It can be difficult to differentiate between communicating hydrocephalus, which requires prompt surgical intervention, and progressive brain atrophy, for which there is no treatment. ${ }^{20}$ This may lead to delayed or inappropriate surgery. ${ }^{20}$ Optic nerve head swelling and optic atrophy have been reported in $20 \%$ and $11 \%$ of patients, respectively. ${ }^{21,22}$ It has been suggested that GAG accumulation in ganglion cells or thickening of the sclera leads to compression of the optic nerve, which in turn causes optic atrophy. ${ }^{17}$ Although poor peripheral and night vision are common symptoms of Hunter syndrome, these are caused by retinal degeneration rather than by optic nerve defects. ${ }^{23}$ As already noted, nearly all patients experience hearing loss, but this is predominantly caused by conductive defects. ${ }^{9}$ However, patients do suffer some sensorineural hearing loss thanks to compression of the cochlear nerve, reduced numbers of spiral ganglion cells and loss of hair cells. ${ }^{924}$ Carpal tunnel syndrome caused by entrapment of the median or ulnar nerves has been reported to affect $96 \%$ of children who have Hunter syndrome but may be underdiagnosed, for patients' cognitive impairment often prevents them from accurately describing their symptoms. ${ }^{17,25}$ Manual clumsiness, avoidance of manual activity and abnormal patterns of grasping may indicate that a child has carpal tunnel syndrome.
Hunter and other mucopolysaccharidoses syndromes are the most common cause of carpal tunnel syndrome in children, indicating that these disorders should be considered in children presenting with this condition. ${ }^{26}$ Spinal cord compression is a common complication and can cause cervical myelopathy (as well as myelopathy on other levels); this can have devastating consequences such as progressive and irreversible loss of motor function and sensation in all four limbs, spasticity or neurogenic bladder..$^{1720}$ Thus it is important that spinal cord compression be detected as early as possible.

\section{Morphological Changes in the Central Nervous System}

All patients who have Hunter syndrome display neurological abnormalities on magnetic resonance imaging (MRI) or at autopsy, even in the absence of clinical neurological symptoms. ${ }^{20,27,28}$ Neurodegenerative changes in the periventricular and subcortical white matter, the corpus callosum and the basal ganglia that give a sieve-like or honeycomb appearance are common (see Figure $3 A$ )..$^{20,27,28} \mathrm{~A}$ review of multiple radiology studies found that the three most consistently reported neurological findings in Hunter syndrome patients were enlargement of the periventricular spaces, ventriculomegaly and brain atrophy (see Figure $3 B) .{ }^{27}$ Although these changes are all seen in other conditions, they are rarely seen in combination with sieve-like changes - hence the co-occurrence of these signs is highly suggestive for Hunter syndrome. ${ }^{27}$ 
Closed cephaloceles, Chiari malformation, giant cisternae and J-shaped sellae are also common radiological findings in Hunter syndrome. 20,29,30 The extent of sieve-like changes has been reported to be inversely correlated to ventricular enlargement and atrophy, suggesting that sieve-like lesions develop first and lead to more extensive neural damage in white matter, followed by atrophy. ${ }^{27}$ The observed correlation between disease duration and white matter lesions and atrophy in a cohort of 31 Hunter syndrome patients supports this theory. ${ }^{31}$ Although some studies have shown that symptom severity corresponds with the extent of changes found on MRI scans, other studies have found no such correlation. ${ }^{27.29}$ Indeed, patients having the non-neuronopathic phenotype have been reported to have extensive neural atrophy and ventriculomegaly but no cognitive retardation. ${ }^{27}$ However, a recent study has reported an association between reduced volumes of white matter and corpus callosum and attention deficits in patients with nonneuronopathic disease who show no IQ or memory deficits..$^{32}$ Further research is required to define the relationship between morphological changes in the brain and disease progression. Cervical spine MRI abnormalities include dens hypoplasia, periodontoid thickening and disc abnormalities in almost all patients having Hunter syndrome, regardless of phenotype. ${ }^{20,33}$ Spinal stenosis is present in almost $50 \%$ of cases. ${ }^{20,33}$

\section{Management of the Neurological Aspects of Hunter Syndrome}

Because of the complexity of sign and symptoms, patients with Hunter syndrome require regular follow-up and the provision of care by a multi-disciplinary team. ${ }^{34}$ Because of the extensive neurological manifestations of Hunter syndrome, particularly in its neuronopathic form, paediatric neurologists should play a major role in this team. ERT is available for the somatic symptoms of Hunter syndrome, but symptomatic treatment is currently the only option for neurological symptoms $^{13}$ (see Table 1). Antipsychotic agents (both typical and atypical agents) and attention stimulants (such as methylphenidate) might improve behavioural concerns associated with Hunter syndrome. However, published studies of such agents in patients having this disorder are lacking. When prescribing, physicians must be aware of the expectations, limitations and potential risks associated with these agents. Thus psychoactive agents should be prescribed only by a neurologist or psychiatrist experienced in these matters. Stimulating environments, special schooling or speech therapy to promote maximal learning during the early stages of the disease, are also recommended to aid behavioural and cognitive development. ${ }^{5}$ Anticonvulsant therapy can reduce the frequency of seizures and might also improve sleep, and cognitive and behavioural symptoms. ${ }^{19}$ Polysomnography can be used to assess patients' sleep disturbances; considering the occurrence of seizures, it is best that a full electroencephalograph be recorded.

Communicating hydrocephalus can be effectively treated by insertion of a ventriculoperitoneal shunt, which can improve motor development in early stages of the disease. ${ }^{17}$ It is suggested that nerve conduction studies be performed in patients every 1 to 2 years from age 4-5 onwards to monitor peripheral nerve function and the development of carpal tunnel syndrome. ${ }^{34}$ If detected early, carpal tunnel syndrome can be treated successfully by decompression surgery. ${ }^{5}$ However, without such an intervention, carpal tunnel syndrome might result in loss of hand function. MRI of the spine should be performed if patients develop any symptoms of spinal cord compression, such as back pain, hyper-reflexia, sudden loss in muscle strength or loss of bladder control. If spinal cord compression is found, decompression surgery must be undertaken promptly, preferably by an experienced team, because these patients are at risk of serious surgical complications, such as pulmonary or cardiac obstruction. ${ }^{35}$ Spinal cord compression can have a devastating effect on patients, and prompt treatment can avoid development of these symptoms. ${ }^{5}$ Thus, if a patient is undergoing MRI for reasons other than suspected spinal cord compression, MRI of the spine should be performed. Somatosensory evoked potential (SSEP) can also be used to assess the extent of any myelopathy present. ${ }^{36}$ It is widely accepted that both MRI and SSEP are useful tools for monitoring the pathologic progression of neurological disease, ${ }^{33,36}$ but there is no evidence for or consensus on ideal frequency of these assessments before patients become symptomatic. Parents and carers should be made aware of the signs and symptoms of spinal cord compression and should be informed that medical advice should be sought immediately so that investigations and treatment can begin promptly. ERT with idursulfase (Elaprase ${ }^{\circledR}$, Shire, Lexington, MA, US) has been reported to reduce some of the somatic manifestations in up to $92 \%$ of patients who have severe Hunter syndrome..$^{13}$ Idursulfase does not cross the blood-brain barrier

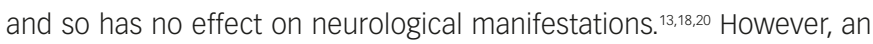
investigational formulation of idursulfase that can be delivered via an intrathecal device directly into cerebrospinal fluid and target cognitive impairment is being investigated. . $73,38,39^{2}$

\section{Conclusions}

Neurologists have an important role in the diagnosis and management of Hunter syndrome because of the extensive neurological involvement in this disease. Patients affected with neuronopathic Hunter syndrome display developmental delay and cognitive impairment, which becomes evident in early childhood and progressively worsens, usually leading to premature death in the second decade of life. Neurological signs and symptoms that may be evident in patients having either the neuronopathic or non-neuronopathic phenotypes include seizures, optic nerve compression, hearing impairment, sleep apnoea, hydrocephalus, carpal tunnel syndrome, spinal cord compression and cervical myelopathy. Neurologists should also be aware of the somatic signs and symptoms of the disease so that they can recognise the condition in undiagnosed patients. All patients who have Hunter syndrome show neurological abnormalities on MRI scans. Though the extent of neurological change does seem to correlate with age, it does not always correlate with clinical severity. Because the manifestations of Hunter syndrome can vary greatly from patient to patient, a highly tailored approach to clinical care is required involving physicians with expertise in the disorder. With such an approach, current management options may alleviate some of the neurological symptoms of Hunter syndrome, but treatments that target accumulation of GAGs in the central nervous system are required if we hope to further improve the prognosis of patients who have neuronopathic Hunter syndrome.
1. Martin R, Beck M, Eng $C$, et al., Recognition and diagnosis of mucopolysaccharidosis II (Hunter syndrome), Pediatrics, 2008;121:e377-86.

2. Neufeld EF, Muenzer J, The Mucopolysaccharidoses. In: Scriver CR, Beaudet AL, Sly WS, eds., The metabolic and molecular bases of inherited disease, 8th ed., New York: McGraw-Hill; 2001:3421-52.

3. Poorthuis BJ, Wevers RA, Kleijer WJ, et al., The frequency of lysosomal storage diseases in the Netherlands, Hum Genet,
1999;105:151-6

4. Baehner F, Schmiedeskamp C, Krummenauer F, et al , Cumulative incidence rates of the mucopolysaccharidoses in Germany, I Inherit Metab Dis, 2005;28:1011-7.

5. Wraith JE, Scarpa M, Beck M, et al., Mucopolysaccharidosis type II (Hunter syndrome): a clinical review and recommendations for treatment in the era of enzyme replacement therapy, Eur J Pediatr, 2008;167:267-77. 6. Lehman TJ, Miller N, Norquist B, et al., Diagnosis of the mucopolysaccharidoses, Rheumatol (Oxford), 2011;50 (Suppl. 5):v41-8.

Hunter C, A rare disease in two brothers, Proc $R$ Soc Med 1917;10:104-16.

8. Young ID, Harper PS, The natural history of the severe form of Hunter's syndrome: a study based on 52 cases, Dev Med Child Neurol, 1983;25:481-9.

2. Holt JB, Poe MD, Escolar ML, Natural progression of neurological disease in mucopolysaccharidosis type ॥., 
Pediatrics, 2011;127:e1258-65

10. Jones SA, Almassy Z, Beck M, et al., Mortality and cause of death in mucopolysaccharidosis type II: a historical review based on data from the Hunter Outcome Survey (HOS), I Inherit Metab Dis, 2009:32:534-43.

11. Muenzer J, Wraith JE, Beck M, et al., A phase II/III clinical study of enzyme replacement therapy with idursulfase in mucopolysaccharidosis II (Hunter syndrome), Genet Med, 2006;8:465-73.

12. Muenzer J, Gucsavas-Calikoglu M, McCandless SE, et al., A phase $1 /$ ll clinical trial of enzyme replacement therapy in mucopolysaccharidosis II (Hunter syndrome), Mol Genet Metab, 2007;90:329-37.

13. Muenzer J, Bodamer O, Burton B, et al., The role of enzyme replacement therapy in severe Hunter syndrome-an expert panel consensus, Eur J Pediatr, 2012;171:181-8.

14. Bax MC, Colville GA, Behaviour in mucopolysaccharide disorders, Arch Dis Child, 1995;73:77-81.

15. Holt J, Poe MD, Escolar ML, Early clinical markers of central nervous system involvement in mucopolysaccharidosis type II, J Pediatr, 2011:159:320-6 e2.

16. Cross EM, Hare DJ, Behavioural phenotypes of the mucopolysaccharide disorders: a systematic literature review of cognitive, motor, social, linguistic and behavioura presentation in the MPS disorders, I Inherit Metab Dis, 2013:36:189-200

17. Al Sawaf S, Mayatepek E, Hoffmann B, Neurological findings in Hunter disease: pathology and possible therapeutic effects reviewed, J Inherit Metab Dis, 2008;31:473-80.

18. Manara R, Rampazzo A, Cananzi M, et al., Hunter syndrom in an 11-year old girl on enzyme replacement therapy with idursulfase: brain magnetic resonance imaging features and evolution, J Inherit Metab Dis, 2010;33(Suppl. 3):S67-72

19. Bonanni P, Gubernale M, Martinez F, et al., Non-convulsive status epilepticus of frontal origin in mucopolysaccharidosis type II successfully treated with ethosuximide, Dev Med Child Neurol, 2012;54:961-4.

20. Manara R, Priante E, Grimaldi M, et al., Brain and spine MRI features of Hunter disease: frequency, natural evolution and response to therapy, J Inherit Metab Dis, 2011;34:763-80.

21. Collins ML, Traboulsi El, Maumenee IH, Optic nerve head swelling and optic atrophy in the systemic head swelling and optic atrophy in the systemic
mucopolysaccharidoses, Ophthalmol, 1990:97:1445-9. mucopolysaccharidoses, Ophthalmol, 1990,9
2. Ashworth JL, Biswas S, Wraith E, Lloyd IC, Mucopolysaccharidoses and the eye, Surv ophthalmo 2006;51:1-17.

23. Suppiej A, Rampazzo A, Cappellari A, et al., The role of visua electrophysiology in mucopolysaccharidoses, I Child Neurol 2013;28:1203-9.

24. Scarpa M, Mucopolysaccharidosis type II, in Pagon RA, Adam MP, Ardinger HH, et al., eds., GeneReviews ${ }^{\varpi}$, Seattle: University of Washington; 1993

25. Kwon JY, Ko K, Sohn YB, et al., High prevalence of carpal tunnel syndrome in children with mucopolysaccharidosis type II (Hunter syndrome) Am J Med Genet, 2011:155A:1329-35.

26. Yuen $\mathrm{A}$, Dowling $\mathrm{G}$, Johnstone $\mathrm{B}$, et al., Carpal tunne syndrome in children with mucopolysaccharidoses, $J$ Child Neurol, 2007;22:260-3.

27. Finn CT, Vedolin L, Schwartz IV, et al., Magnetic resonance imaging findings in Hunter syndrome, Acta Paediatr Suppl, 2008:97:61-8.

28. Hamano K, Hayashi M, Shioda K, et al., Mechanisms of neurodegeneration in mucopolysaccharidoses II and IIIB: analysis of human brain tissue, Acta Neuropathol, 2008;115:547-59

29. Manara R, Priante E, Grimaldi M, et al., Closed meningo(encephalo)cele: a new feature in Hunter syndrome, AJNR Am J Neuroradio, 2012;33:873-7.
30. Parsons VJ, Hughes DG, Wraith JE, Magnetic resonance maging of the brain, neck and cervical spine in mild Hunter's syndrome (mucopolysaccharidoses type II). Clin Radiol, 1996:51:719-23.

31. Vedolin L Schwartz IV Komlos M, et al., Brain MRI in mucopolysaccharidosis: effect of aging and correlation with biochemical findings, Neurology, 2007;69:917-24.

32. Yund B, Rudser $\mathrm{K}$, Ahmed A, et al., Cognitive, medical, and neuroimaging characteristics of attenuated mucopolysaccharidosis type II, Mol Genet Metab

33. Zuber Z, Jurecka A, Jurkiewicz E, et al., Cervical spine MR findings in patients with mucopolysaccharidosis type II, Pediatr Neurosurg, 2015;50:26-30.

34. Muenzer J, Beck M, Eng CM, et al., Multidisciplinary management of Hunter syndrome, Pediatrics, 2009;124:e1228-39.

35. Belani KG, Krivit W, Carpenter BL, et al., Children with mucopolysaccharidosis: perioperative care, morbidity, mortality, and new findings, J Pediatr Surg, 1993:28:403-8; discussion 8-10

36. Boor R, Miebach E, Bruhl K, Beck M, Abnormal somatosensory evoked potentials indicate compressive cervical myelopathy in mucopolysaccharidoses, Neuropediatr, 2000;31:122-7.

37. Calias P, Papisov M, Pan J, et al., CNS penetration of intrathecal-lumbar idursulfase in the monkey, dog and mouse: implications for neurological outcomes of Iysosoma storage disorder, PLOS One, 2012:7:e30341.

38. Felice BR, Wright TL, Boyd RB, et al., Safety evaluation of chronic intrathecal administration of idursulfase-IT in cynomolgus monkeys, Toxicol Pathol, 2011;39:879-92.

39. Muenzer J, Hendricksz CJ, Fan Z, et al., A phase 1/II study of intrathecal idursulfase-IT in children with severe mucopolysaccharidosis II, Genet Med, 2015 [Epub ahead of print. 